\title{
An Analysis of Humor in The Big Bang Theory Based on the Cooperative Principle
}

\author{
Zhang Ning, Wang Caixia, Gao Yuan \\ Shandong Jiaotong University, Weihai, Shandong
}

Keywords: humor, cooperative principle, quantity maxim, quality maxim, relation maxim, manner maxim

\begin{abstract}
Humor derives from everyday life. This paper analyses the humorous effect in The Big Bang Theory which is a popular American sitcom from the perspective of the cooperative principle by Grice including quantity maxim, quality maxim, relation maxim and manner maxim. This paper aims to investigate and analyze the humorous effect caused by the violation of the cooperative principle in people’s daily communications.
\end{abstract}

\section{Introduction}

As an art of language, humor can be seen everywhere in our daily life. Humor is a kind of ingenious and creative language. It uses implicit and implied language to make people understand humor in daily communication. Humor has a special effect and plays an important role in the communication between people, which can not merely be ignored. Walter Nash pointed out that humor is a unique feature for human beings in his book The Language of Humor. Until now, there is no satisfactory definition of humor. The definition of humor in $\mathrm{Ci}$ Hai is as follows: Humor is an aesthetic noun. The errors and unreasonableness in life are revealed in a good-natured smile by means of insinuation, allegory or some other rhetorical devices. Therefore, it is safe to conclude that humor originates from everyday life.

\subsection{The cooperative principle}

The theory of cooperative principle was first proposed by American philosopher H.P. Grice in his lectures at Harvard University in 1967 and still only partially published. Grice holds that the cooperative principle makes your contribution such as is required, at the stages at which it occurs, by the accepted purpose or direction of the talk exchange in which you are engaged. Otherwise, the conversation cannot continue fluently. As a consequence, people are required to hold a cooperative attitude in speech acts. Cooperative principle consists of four categories which are quantity maxim, quality maxim, relation maxim and manner maxim. Furthermore, each of the category consists of a criterion and a number of sub-criteria which will be discussed later in part 2. However, people are not always abiding by these rules. People will violate these norms intentionally or unintentionally sometimes for some communicative purpose or in order to express a particular meaning, thus creating a conversational implication which is different from the literal meaning of words to produce a humorous effect.

\subsection{Introduction to the sitcom: The Big Bang Theory}

The Big Bang Theory is a most popular American sitcom. It has been all the rage around the world since 2007 and it won the best comedy series TCA award in August 2009. The Big Bang Theory concentrates on a group of scientific geniuses. Heroes Leonard and Sheldon are a pair of crazy scientists with a combined IQ of more than 360. They can even recite the theory of quantum physics backwards fluently. However, when it comes to daily life, the two men are at a loss. Their neighbour is Penny, a beautiful actress and waitress. Their scientist friends also include Howard and Rajesh. There is abundance of humorous and contradictory words in it, which is meaningful and necessary for language learners to investigate the inner mechanism from the perspective of cooperative principle. 


\section{Analysis of the humorous effect caused by the violation of the four maxims}

This part illustrates the four maxims seperately and investigates the humorous effect caused by the violation of the four maxims of cooperative principle in The Big Bang Theory.

\subsection{Quantity maxim}

The criterion of quantity maxim consists of two sub-criteria, which are as follows:

(1) Make your contribution as informative as is required for the current purposes of the exchange

(2) Do not make your contribution more informative than is required.

Quantity maxim requires that we should provide information as needed and not provide unnecessary information. However, in The Big Bang Theory, some humorous effects are caused by the violation of quantity maxim.

Example 1: (In the restaurant where Penny works as a waitress)

Penny: Hey. So you guys ready to order?

Sheldon: Since we come in every Tuesday night at 6:00 and order the same exact thing and it's now 6:08. I believe your question not only answers itself but also stands alongside such other nonsensical queries as "Who let the dogs out?" And, uh, "How are they hanging?"

In this conversation, Penny as a waitress asked if Sheldon and his friends are ready to order. Sheldon as a customer should answer Penny's question directly and briefly. However, Sheldon's answer not only includes his agreement to Penny's question but also much more information than is required, such as "Since we come in every Tuesday night at 6:00...stands alongside such other nonsensical queries as "Who let the dogs out?" ... "How are they hanging?”. Sheldon's answer violates quantity maxim, thus produce humourous effect.

Example 2: (In cafeteria)

Howard: Why's the president of the university slumming in the cafeteria?

Sheldon: Perhaps he's emulating Shakespeare's Henry V, who dressed as a commoner and mingled among them, to find out how he was being perceived by his subjects. Of course, if he'd have read any of the 1300 e-mails I've sent him on the subject of his administration, he could have saved himself the trouble.

In this conversation, the four scientists are eating in the cafeteria. Howard proposed a question "Why's the president of the university slumming in the cafeteria?". Sheldon's answer to this question is "to find out how he was being perceived by his subjects". However, besides this answer, Sheldon provides much more information than is required, such as "Perhaps he's emulating Shakespeare's Henry V, who dressed as a commoner and mingled among them... Of course, if he'd have read any of the 1300 e-mails I've sent him on the subject of his administration, he could have saved himself the trouble." Sheldon's answer provides more information than is required, thus produce humourous effect.

\subsection{Quality maxim}

The criterion of quality maxim consists of two sub-criteria, which are as follows:

Try to make your contribution one that is true, specifically:

Do not say what you believe to be false

Do not say that for which you lack adequate evidence

Quality maxim requires that people should speak truthfully, reasonably and with adequate evidence. However, in The Big Bang Theory, some humorous effects are caused by the flouting of quality maxim.

Example 1(in comic shop)

Zack: Wow, this place is awesome. Where do they keep the Archies?

Sheldon: In the bedroom of ten-year-old girls, where they belong.

Zack (a friend of Penny) came to a comic shop with the four scientist geniuses. Zack asked Sheldon: "Where do they keep the Archies (cartoon)?". Sheldon answered with words that he himself believed was false: "In the bedroom of ten-year-old girls, where they belong." Sheldon's answer violates quality maxim, thus creating humorous effect. 
Example 2: (at university)

Leonard: So anywany, Howard asked Penny to talk to Bernadette, and she did, and Bernadette agreed to meet him for a cup of coffee.

Sheldon: One question.

Leonard: Yeah?

Sheldon: Why on earth are you telling me all this?

Leonard: I don't know. Sometimes your movements are so lifelike. I forget you are not a real boy.

Leonard told Sheldon a good news that "Bernadette agreed to meet him (Howard) for a cup of coffee" excitedly. However, the news fell flat on Sheldon and he asked: "Why on earth are you telling me all this?" Leonard answered: "Sometimes your movements are so lifelike. I forget you are not a real boy." Obviously, what Leonard said is false. He violated the truth that Sheldon was a person, thus creating humorous effect.

\subsection{Relation maxim}

The criterion of relation maxim consists of only one criterion, which is "make your contributions relevant”.

Relation maxim emphasizes the relevance of speech. People should not avoid a serious problem or deliberately detour. However, in The Big Bang Theory, some humorous effects are caused by the flouting of relation maxim.

Example 1: (In cafeteria)

Howard: Leonard, settle this. Of the two of us, who's the obvious sidekick?

Rajesh: Yeah, Leonard, who?

Leonard: 12 years after high school, and I'm still at the nerd table.

In cafeteria, Howard and Rajesh fought tooth and nail over the question "who is like a sidekick?" and asked Leonard as a judge. Leonard did not answer their question directly. Instead, his response seemed irrelevant to their question " 12 years after high school, and I'm still at the nerd table." Leonard was violating relation maxim, thus creating humorous effect.

Example 2: (in the apartment)

Sheldon: Wait! What am I supposed to do?

Leonard: Well, have you considered telling her how you feel?

Sheldon: Leonard, I'm a physicist, not a hippie.

Amy, Sheldon's girlfriend, asked him to see her mother. However, Sheldon was reluctant to do this and turn to Leonard for help. Leonard asked Sheldon: "have you considered telling her how you feel?" Sheldon did not answer Leonard's question. Instead, Sheldon emphasized that he was a physicist, not a hippie. Sheldon's answer is irrelevant to Leonard's question. Hence Sheldon violated relation maxim, thus creating humorous effect.

\subsection{Manner maxim}

The criterion of manner maxim consists of four sub-criteria, which are as follows:

Be perspicuous, and specifically:

(1) avoid obscurity

(2) avoid ambiguity

(3) be brief

(4) be orderly

Manner maxim expresses requirement for people's means of expression. People should speak frankly and clearly and should not speak devious and obscure words in case that ambiguity or misunderstanding should be caused. However, in The Big Bang Theory, some humorous effects are caused by the violation of manner maxim.

Example 1: (at home of Sheldon and Leonard)

Leonard: Well, I'm off to meet Bernadette's friend. How do I look?

Sheldon: As if one of the plants from Invasion of the Body Snatchers duplicated you in every way, only with an absurd amount of hair gel. 
Leonard was happy to meet Bernadette's friend. After dressing up, Leonard asked Sheldon: “How do I look?” Sheldon's answer is “As if one of the plants from Invasion of the Body Snatchers duplicated you in every way, only with an absurd amount of hair gel." Sheldon's answer was obscure and indirect, hence producing humorous effect.

Example 2: (at home of Sheldon and Leonard)

Sheldon: Yes, the elevator's out of order; you'll have to use the stairs...Pizza dates back to the 16th century, while the first elevator was not installed until 1852. That means that over 300 years, people carried pizzas upstairs. Be part of that proud tradition.

At home of Sheldon and Leonard, Sheldon ordered a takeout pizza. However, the delivery person telephoned to tell Sheldon that the elevator was out of order. Sheldon's answer is "Yes, the elevator's out of order; you'll have to use the stairs...Pizza dates back to the 16th century, while the first elevator was not installed until 1852. That means that over 300 years, people carried pizzas upstairs. Be part of that proud tradition.” Sheldon's answer was wordy and obscure. He violated the requirement of "be brief and be orderly" in manner maxim, thus creating humorous effect.

Of course, humorous effects may be caused by violating more than one maxim in cooperative principle. Take example 1 of quantity maxim as an example, Sheldon's words not only violated quantity maxim, but also violated the manner maxim because he was too verbose and wordy. Neverthless, the violation of cooperative principle does not necessarily mean that the communication cannot be continued. Listeners can understand the implied meaning of words beyond their superficial meaning, which is called conversational implicature. Conversational implicature concerns the way we understand an utterance in conversation in accordance with what we expect to hear. Take example 1 in quality maxim as an example, Zack could understand that Sheldon was laughing at him that he was still reading children's cartoon and Zack fought back.

\section{Conclusions}

Humor derives from life. Through the above analysis we can safely conclude that humorous effects are caused by violating one certain or more maxims of cooperative principle to a certain degree. However, merely cooperative principle itself can not explain all levels of humor. There are speech act theory, politeness principle and some other theories to help investigate humor in pragmatics. English teachers can help students to understand the context in depth, taste the charm of language and improve students' comprehension and communication ability if they can employ cooperative principle in their teaching.

\section{References}

[1] Leech, Geoffrey. Studies in the Way of Words. New York: Longman Group Limited. 1983.

[2] Nash W. The Language of Humor. New York: Longman Inc. 1985.

[3] Stephen C. Levinson. Pragmatics. Beijing: Foreign Language Teaching and Research Press. 2006.

[4] Wang Xiang. Pragmatic Interpretation of English Humor. Journal of Hubei University of Economics. 2008, 5 (3):148-149 Teaching and Research Press. 2000. 